\title{
Las fuentes de la hagiografía del dominico medieval, Gonzalo de Amarante: tradición y santidad en el siglo XIII*
}

\author{
Eugenio Martín Torres Torres, O. P.**
}

Recibido: 31 de octubre de 2017 • Aprobado: 27 de noviembre de 2017

\section{Resumen}

En años recientes el género literario de las hagiografías o vidas de santos, ha sido revalorado por historiadores del arte, de las mentalidades y de la Iglesia católica, entre otros. En este artículo se pretenden identificar las fuentes que a través de los siglos influyeron en la biografía de Gonzalo de Amarante (c. 1186-c. 1259/1262), uno de los beatos dominicos medievales más populares en la península Ibérica y en la América española y portuguesa, hasta convertirla en una importante fuente histórica de devoción popular, con notables influencias bíblicas y hagiográficas antiguas y medievales.

Palabras clave: hagiografía, Gonzalo de Amarante, santo Domingo, Biblia, tradición.

* Producto de un proyecto de investigación del Instituto de Estudios Socio-Históricos Fray Alonso de Zamora, Universidad Santo Tomás. DOI: http://dx.doi.org/10.15332/s2011-9771. 2017.0002.08

** Licenciado en Historia y Teología Dogmática, sacerdote de la Orden de Predicadores, en la provincia de San Luis Bertrán de Colombia. Correo electrónico: idhqro@yahoo.com.mx 


\title{
The sources of the hagiography of the medieval Dominican, Gonzalo de Amarante: tradition and sanctity in the 13th century
}

\begin{abstract}
In recent years the literary genre of hagiographies or lives of saints has been revalued by historians of art, mentalities and the Catholic Church, among others. In this article we try to identify the sources that through the centuries influenced the biography of Gonzalo de Amarante (c. 1186-c. 1259/1262), one of the most popular medieval blessed Dominican in the Iberian Peninsula and in the Spanish and Portuguese Americas, until turning it into an important historical source of popular devotion, with notable biblical and ancient and medieval hagiographic influences.
\end{abstract}

Keywords: hagiography, Gonzalo de Amarante, Saint Dominic, Bible, tradition.hagiografía, Gonzalo de Amarante, Saint Domingo, Biblia, tradición.

\section{As fontes da hagiografia do dominicano medieval, Gonzalo de Amarante: tradição e santidade no século XIII}

\section{Resumo}

Em anos recentes o gênero literário das hagiografias ou vidas de santos, tem sido revalorizado pelos historiadores da arte, das mentalidades e da Igreja católica, entre outros. Neste artigo pretende-se identificar a fontes que através dos séculos influíram na biografia do Gonzalo de Amarante (c. 1186-c. 1259/1262), um dos beatos dominicanos e medievais mais populares na península Ibérica e na América espanhola e portuguesa, até convertê-la em uma importante fonte histórica de devoção popular, com notáveis influências bíblicas e hagiográficas antigas e medievais.

Palavras-chave: hagiografia, Gonzalo de Amarante, santo Domingo, Bíblia, tradição. 


\section{Introducción}

El propósito de este artículo es analizar la hagiografía o vida del beato dominico portugués, fray Gonzalo de Amarante (c. 1186 -c. 1259/1262). En particular, se busca identificar su relación o influencias provenientes de la Biblia, los Evangelios apócrifos populares, la tradición hagiográfica antigua y las fuentes de este mismo tipo escritas por miembros de la Orden de Predicadores, durante el siglo XIII. Con este fin, partimos de dos hipótesis.

La primera es que la redacción del conjunto hagiográfico de san Gonzalo fue gradual ${ }^{1}$. Es decir, sus hagiógrafos dependieron tanto de la difusión de su devoción popular -su primer y gran impulso-, como de los reconocimientos oficiales provenientes de Roma de sus virtudes cristianas, la autorización pontificia para celebrar su fiesta en el reino de Portugal y el permiso para que el venerable lusitano dispusiera de un oficio litúrgico propio en su Orden. ${ }^{2}$ Estos dos últimos pasos se dieron respectivamente el 16 de septiembre de 1561 y el 10 de julio de 1671 (Bordazar, 1739, p. 68).

En la vida o biografía de Amarante, se destaca el desconocimiento de las principales fechas de su vida. Característica que en parte explica por qué sus autores hagiográficos no solo repitieron la escasa información conocida (el lugar de su nacimiento, estudios recibidos, su peregrinaje a Tierra Santa y apostolados realizados), sino también fueron contextualizando sus principales milagros y redondeando la personalidad del taumaturgo.

La segunda hipótesis pretende demostrar que el modelo de vida cristiana de Gonzalo de Amarante fue el de santo Domingo de Guzmán, el fundador de los dominicos en 1216. En este aspecto, se destaca la existencia en la personalidad del venerable portugués de rasgos o cualidades de tipo cognoscitivo, afectivo, volitivo y espiritual subrayados en Domingo de Guzmán por sus hagiógrafos medievales.

Así mismo, en una escala menor pero no menos importante, fray Gonzalo también comparte actitudes de vida presentes en varios personajes veterotestamentarios, los apóstoles y algunos santos de los primeros siglos del cristianismo. Esto no significa que su vida sea una invención literaria o una leyenda fantástica sin conexión con su verdadera personalidad y la realidad histórica, aunque los autores omitieran datos precisos de su vida y la salpicaran de milagros poco creíbles.

1 Con el apelativo de santo aún es conocido en Portugal, en Brasil y en algunas parroquias ubicadas en el centro de México y en las regiones españolas de Galicia y Andalucía.

2 La autorización fue extendida tanto para el clero regular como secular. El autor del rezo en el oficio propio de los dominicos fue Andrés Resendio. 
Al contrario, la falta de información biográfica y las continuas referencias a sus milagros, recuerdan que lo esencial para las mentalidades antigua y medieval era mostrar modelos posibles de vida evangélica y transmitir mensajes envueltos en milagros rayanos en lo fantástico, pero en la mayoría de los casos siempre con alguna relación bíblica y contenidos catequéticos. En lenguaje contemporáneo se trata de la construcción de un paradigma, el cual a lo largo de este artículo será analizado, sin olvidar que los escritores medievales transmitían mensajes muy importantes mediante alegorías y discursos que, a partir del racionalismo del siglo XVII, fueron perdiendo vigencia sobre todo en medios ilustrados, pero no entre el pueblo llano.

Otro aspecto significativo en los relatos hagiográficos de fray Gonzalo de Amarante es la referencia a características históricas del siglo XIII, como fueron: el crecimiento poblacional europeo, la paulatina monetización de la sociedad, la consolidación de las parroquias como unidades jurisdiccionales eclesiales independientes de los señores feudales, la sistematización de la curricula clerical fuera de los monasterios, la vigencia de la opción de la vida eremítica, el furor por las peregrinaciones a Tierra Santa, la difusión de herejías como las de los cátaros y albigenses, y la expansión de las órdenes mendicantes. A esto hay que agregar la importancia de las devociones populares marianas y la persistente corrupción existente en diversos sectores del clero. Todas estas características aparecen en la vida de san Gonzalo.

Con respecto a las obras hagiográficas de Amarante, este artículo considera solo las publicadas en castellano o traducidas del portugués. Los autores consultados son: Alonso de Villegas (1615), Antonio de Vieyra (1734), Manuel Bordazar (1739), Manuel Amado (1829), J. Croiset (1842) y Paulino Álvarez (1920). Todos ellos dependientes de la Leyenda Aurea o Flos Sanctorum, escrita y recopilada, entre 1253 y 1270, por el también dominico fray Santiago de la Vorágine, quien originalmente no incluyó a san Gonzalo en su elenco de vidas ${ }^{3}$. Su incorporación fue en las traducciones al portugués de 1513 y 1567 que sí comprendieron a venerables y santos portugueses ${ }^{4}$.

3 Asimismo llamado Jacobo de Varazze, la obra también se titula Legenda Aurea, Las leyendas de los Santos o Historia Lombarda. José Manuel Macías, O. P., ubica su redacción en 1264 (v. 1, 2001, p. 15).

4 El título completo de la edición de 1567 es Flos Sanctorum. Historia das Vidas de Christo S. N. e de Sua Santíssima May, Vidas de Santos e suas festas repartidas pellos doze meses Com Sermoes, e Practicas que fervem para muytas Festas do Anno. Composto pello R. P. frey Diogo de Rosário e agora acrescentado con muytas vidas de Santos em efta ultima impreffao, Lisboa, António Craesbeeck de 
En la primera edición portuguesa, la especialista Cristina Sobral propone la posibilidad de que el autor de la biografía de Amarante haya sido un dominico anónimo del convento de Nuestra Señora de las Nieves, en Guimarães y registra el año de 1430 como el más probable para su composición (Aceves, 2016, notas 19 y 20, pp. 116-117). En la edición de 1567, el autor fue el dominico fray Diogo do Rosario. En 1753, hay noticias de otra obra titulada el Diario..., escrita por fray Manuel de Lima y aprobada por el obispo de Lisboa en ese año, en ella se describen 407 milagros obrados por fray Gonzalo ${ }^{5}$.

En la difusión de la vida de Amarante también fue importante el libro de Ferdinando Del Castiglio (1589), escrito originalmente en español y traducido al italiano con el título de Historia Generale di S. Domenico e dell'Ordine suo, donde el autor incluyó la vida de san Gonzalo. A partir del siglo XVII, la obra de Alonso de Villegas fue fundamental en el conocimiento de su vida; este escritor en su prólogo, les advierte a los lectores que su fuente principal fue escrita en portugués, pues "anda impresa la vida de este santo en lengua portuguesa bien copiosa" (1615, p. 398). Finalmente, ya entrado el siglo XVIII, fray Manuel Bordazar le dedicó un libro completo al santo portugués y reconoce que escribió a partir, "de los libros que he podido hallar con dificultad y brevedad" (1739, p. VI). La participación de autores dominicos como el fraile anónimo (1513), de Diego del Rosario o Diogo do Rosario (1567) y de Manuel Bordazar (1739), posiblemente expliquen ese apego de Amarante a las virtudes de Domingo de Guzmán.

En cuanto a su proceso de beatificación, los papas Paulo III (1534-1549) y Julio III (1550-1555), por petición del rey Juan III, ordenaron las primeras investigaciones acerca del obrar milagroso. Un tercer intento fue mandado por Pío $\mathrm{V}$ (1566-1572) a instancias de la reina Catalina, pero ninguno logró frutos (Bordazar, 1739 , p. 62). No fue sino hasta el 10 de julio de 1671 que Clemente $X$ concedió, a la Orden de Predicadores, su propio oficio litúrgico con el argumento de que su vida era: "norma de sacerdotes, dechado de anacoretas y peregrinos, espejo

Mello imprefeííor da Cafa Real, 1681. Bordazar afirma que en él se escribieron "grande cantidad de milagros" obrados por Amarante, (1739, p. 62).

5 Se desconoce el título completo de la obra y si realmente se publicó, su existencia es señalada por fray Manuel Soto en 1816, durante un proceso inquisitorial en la Nueva España, donde se pretendía prohibir la devoción popular de danzar frente a la imagen de fray Gonzalo, Archivo General de la Nación, México, Instituciones Coloniales, Ramo Indiferente Virreinal, cajas 2000-2999, exp. 008, Inquisición, citado por Margarita Orozco Trejo, "San Gonzalo de Amarante: bailando desde Portugal a Nueva España", ponencia presentada en el I Congreso Internacional de Historia de la Orden de Predicadores en América, CUC, México, D. F., del 22 al 24 de abril de 2014 (inédita). 
ilustre de predicadores y religiosos", cinco modalidades de vida cristiana de gran actualidad en el siglo XIII (Álvarez, 1920, p. 227; Bordazar, 1739, p. 1).

El reconocimiento papal fue resultado de la continua devoción popular portuguesa y española, profesada tanto en Europa como en América que sin duda influyó en la publicación de las hagiografías del siglo XVIII y XIX en: Valencia (1739), Barcelona (1794), Madrid (1829), París (1842) y Vergara, Navarra (1920). Ello demuestra que, a pesar del racionalismo, de la secularización y el auge de una nueva piedad religiosa, entre el pueblo seguía vigente la devoción a Gonzalo de Amarante, aunque su canonización siguiera pendiente por falta de promoción tanto por parte del reino portugués como de la Orden de Predicadores.

\section{La vida de Amarante}

La mayoría de los autores la dividen en ocho etapas (véase la Tabla 1). A pesar de que ninguno señala el año, es posible que haya nacido hacia finales del siglo XII o inicios del XIII. Todos coinciden que fue originario del pueblo portugués de Tagilde -el antiguo Atanagilde-, ubicado en el arzobispado de Braga, en la feligresía de San Salvador, junto al río Visela en una región bordeada por los ríos Duero y Miño (Bordazar, 1739, p. 1) ${ }^{6}$. Sus padres eran muy cristianos, además de "ricos y nobles". Se desconoce si tuvo hermanos, aunque hay referencias a un sobrino (Bordazar, 1739, p. 2) 7 . Bíblicamente sus progenitores -a diferencia de los padres del profeta Samuel e incluso de los de la Virgen María- no lo consagraron a Dios desde antes de su concepción, sino a partir de la celebración de su bautismo, donde se percataron de la predestinación espiritual de su hijo ${ }^{8}$. Esto ocurrió en el momento en que su madrina lo retiró de la pila bautismal. Fue entonces cuando el recién nacido "puso los ojos en un Cristo crucificado con una fijeza y devoción como si fuera persona muy mayor", esto lo "notaron muchos que allí estaban" (Bordazar, 1739, pp. 2-3).

6 Villegas resume desde su nacimiento hasta su retorno de peregrino, 1615, p. 398; Amado, 1829, p. 5; Croiset, 1842, p. 156; Álvarez, 1920, p. 221.

7 Para este autor nació en el palacio de Gonzalo Pereyra, que era el nombre de su padre.

8 Cf. 1S 1, 11.21-28. En Santos, 1963, el "Protoevangelio de Santiago", cap. 4, núm. 1, p. 142; el "Evangelio del Pseudo Mateo", cap. 2, núm. 2, p. 186; el "Libro sobre la Natividad de María", cap. 3, núm. 2, p. 248.

9 Amado, 1829, p. 5; Croiset, 1842, p. 156; Butler, 1968, p. 112; Álvarez, 1920, p. 221. 
La consagración de Gonzalo consistió en destinarlo para el estado eclesiástico, como un servicio prestado a Jesucristo y a la Virgen María, cuyas imágenes -según los hagiógrafos- al serle mostradas acallaban su llanto infantil o cesaban sus inquietudes y en respuesta, el niño "levantaba sus bracitos a ellas" (Bordazar, 1739, pp. 3-5; Álvarez, 1920, p. 221). En la predestinación de Gonzalo hay dos paralelismos con las hagiografías de Domingo de Guzmán, el fundador de la Orden de Predicadores en 1216. Fray Pedro Ferrando afirma en su Legenda Sancti Dominici -escrita entre 1235 y 1238-, que su madrina de bautismo tuvo el siguiente sueño:

[A ella] le pareció que el niño Domingo tenía en su frente una estrella cuya luz alumbraba toda la tierra. Con eso daba a entender [afirma Ferrando] que sería luz de las gentes y que alumbraría a los que viven en tinieblas y en sombras de muerte. Quien tuvo esta visión era dama de la nobleza, la cual, estupefacta por lo que había contemplado, llena de gozo corrió a comunicárselo a la madre del niño ${ }^{10}$.

Tabla 1. Las ocho etapas de la vida del beato Gonzalo de Amarante y su comparación con la vida de santo Domingo.

\begin{tabular}{|l|l|l|}
\hline \multicolumn{1}{|c|}{ Etapa } & \multicolumn{1}{|c|}{ Gonzalo de Amarante* $^{*}$} & \multicolumn{1}{c|}{ Domingo de Guzmán* } \\
\hline 1 Nacimiento e infancia & $\begin{array}{l}\text { En Amarante, Portugal, fe- } \\
\text { cha desconocida }\end{array}$ & $\begin{array}{l}\text { En Caleruega, Burgos, Espa- } \\
\text { na, entre 1173 y 1175 }\end{array}$ \\
\hline Formación & A cargo de un sacerdote & $\begin{array}{l}\text { A cargo de un tío sacerdote, a } \\
\text { partir de 1179-1180 }\end{array}$ \\
\hline $\begin{array}{l}\text { 3 Ordenación } \\
\text { y ministerio }\end{array}$ & $\begin{array}{l}\text { En el arzobispado de Braga, } \\
\text { de párroco }\end{array}$ & $\begin{array}{l}\text { En Osma, de canónigo y sub- } \\
\text { prior del Cabildo catedralicio, } \\
\text { entre 1195 y 1197 }\end{array}$ \\
\hline $\mathbf{4}$ Peregrino o viajero & $\begin{array}{l}\text { A Roma y Tierra Santa, don- } \\
\text { de permanece 14 años }\end{array}$ & $\begin{array}{l}\text { Dos veces a las Marcas (Dina- } \\
\text { marca), varias veces a Roma, } \\
\text { Bolonia, el sur de Francia, } \\
\text { Castilla, de 1203 a 1207 }\end{array}$ \\
\hline $\mathbf{5}$ Retorno al ministerio & Fecha desconocida & $\begin{array}{l}\text { Desde 1206, el papa Inocen- } \\
\text { cio III aprueba su modo de } \\
\text { predicar }\end{array}$ \\
\hline
\end{tabular}

10 En Galmés, 1987, Pedro Ferrando, p. 220, núm. 6, p. 223. 


\begin{tabular}{|l|l|l|}
\hline \multicolumn{1}{|c|}{ Etapa } & \multicolumn{1}{|c|}{ Gonzalo de Amarante* $^{*}$} & \multicolumn{1}{|c|}{ Domingo de Guzmán* $^{*}$} \\
\hline 6 Expulsión y retiro & $\begin{array}{l}\text { Fecha desconocida, construc- } \\
\text { ción de su ermita }\end{array}$ & $\begin{array}{l}\text { Cuarto viaje a Montreal y la } \\
\text { primera disputa pública en } \\
1207\end{array}$ \\
\hline 7 Invitación de María & Fecha desconocida & $\begin{array}{l}\text { En varias ocasiones tuvo vi- } \\
\text { siones marianas }\end{array}$ \\
\hline $\begin{array}{l}\text { 8 Vida de fraile domini- } \\
\text { co y muerte }\end{array}$ & $\begin{array}{l}\text { Fecha desconocida, asigna- } \\
\text { ción a su ermita, muere en su } \\
\text { ermita un 10 de enero, entre } \\
1259 \text { y } 1262\end{array}$ & $\begin{array}{l}\text { Muere el 6 de agosto de 1221 } \\
\text { en Bolonia }\end{array}$ \\
\hline
\end{tabular}

Nota: La información de Amarante aparece en el artículo: La de Santo Domingo, cf. Galmés, 1987, "cronología", pp. 52-53.

Con notoria similitud, fray Constantino de Orvieto sostiene -en su Vita et miracula Sancti Dominici, escrita entre 1246 y 1247-que su madrina vio como "sobre su frente [aparecía] una estrella muy brillante [... que] alumbraba toda la tierra"11. Además de la evidente influencia del prólogo del Evangelio de san Juan (1,5-8) en el texto de Ferrando, Orvieto agrega que esa estrella era una prefiguración de la misión que santo Domingo desempeñaría de adulto, tal y como les ocurrió -en otro tiempo- tanto al profeta Elías, quien "surgió como un fuego [y] su palabra quemaba como antorcha", como a san Juan Bautista, "el precursor de la gracia"12. Sin embargo -remarca Orvieto-, el mérito no fue de las personas de Elías ni de Juan Bautista, sino de Aquél que le pregunta a Job: “¿Eres tú quien a su tiempo hace salir el lucero?" (38,32).

Es decir, el único mérito es de Dios, así Elías, Juan Bautista y Domingo de Guzmán únicamente representan - en diferentes épocas y realidades históricasel fuego, la luz y la estrella que reflejan a Cristo, "el verdadero Sol que nace de lo Alto". Por último, fray Rodrigo de Cerrato en su Vita Sanctorum -redactada entre 1259 y 1276-, afirma que la predicación del Evangelio por parte de Domingo llegaría a ser como la de un "lucero, o mejor [como la de un] véspero"13, el cual atardeciendo el día" -como Juan Bautista-, "se anticipó a Cristo para anunciar de

11 En Galmés, 1987, Constantino de Orvieto, p. 250; núm. 6, p. 253.

12 En Galmés, 1987, Orvieto, núm. 6, p. 253. Asimismo cf. Jn 1,6-7. El pasaje de la estrella es repetido por Humberto de Romans, Galmés, 1987, núm. 4, pp. 296-297.

13 Es decir, un antecesor en alusión a la palabra vísperas que en sentido temporal precede a un acontecimiento. 
antemano", no su primera venida, que fue la histórica, "sino su segunda venida", la escatológica, la última, la del final de los tiempos ${ }^{14}$.

\section{La educación y ordenación como presbíteros de Domingo y de Gonzalo}

Amarante, al igual que santo Domingo (c. 1173/1175-1221) recibió su primera formación de un clérigo. Gonzalo "aprendió a leer y escribir con perfección; porque como gastaba poco tiempo en las diversiones le sobraba mucho tiempo que dar a los empleos del estudio. Con la misma facilidad aprendió la lengua latina" (Bordazar, 1739, p. 5). Santo Domingo entre 1179 y 1180 fue confiado a un tío sacerdote $^{15}$.

Después, el portugués continuó sus estudios en la casa -una escuela catedralicia- del arzobispado de Braga, donde es probable que haya recibido la educación clásica impartida en el siglo XIII, integrada por las artes liberales mediante el trivium -retórica, gramática y dialéctica- y el cuadrivium -aritmética, geometría, música y astronomía- (Bordazar, 1739, p. 5) ${ }^{16}$. Santo Domingo a partir de 1186, ingresó al estudio general de Palencia, donde culminó su formación con el estudio de teología y las sagradas escrituras ${ }^{17}$.

Al finalizar sus estudios parecen distanciarse sus perfiles biográficos. Entre 1195 y 1197, Domingo ingresó como canónigo al cabildo de la catedral de Osma, en Castilla, donde fue ordenado sacerdote ${ }^{18}$. A su vez Gonzalo, después de ser ordenado por el arzobispo de Braga, recibió una parroquia y la abadía de la iglesia de San Pelagio o San Payo de la Riba de Visela (Bordazar, 1739, pp. 6-7) ${ }^{19}$.

14 En Galmés, 1987, Rodrigo de Cerrato, núm. 1, p. 337.

15 En Galmés, 1987, Jordán de Sajonia, p. 52, 85, núm. 5.

16 Amado, 1829, p. 5; Croiset, 1842, p. 156; Álvarez, 1920, p. 221.

17 En Galmés, 1987, Cronología, p. 52; Sajonia, núms. 6-7, pp. 85-86; Orvieto, núms. 8-9, pp. 253-254; Humberto de Romans agrega que también estudió metafísica, núm. 6, pp. 297-298, Cerrato, núm. 2, p. 338.

18 En Galmés, 1987, Sajonia, núm. 11, p. 87; Romans, núm. 8, pp. 298-299; Cerrato, núm. 5, pp. 339-340. A partir del siglo XI, el Concilio de Tolosa fijó la edad de 30 años, como regla general, para recibir el sacramento del orden presbiteral, aunque la ordenación se podía adelantar a criterio de cada obispo y de su clero, Chardon, 1800, p. 249.

19 Las abadías eclesiales eran muy diferentes a las monásticas, caracterizadas en la Edad Media por contar con una comunidad grande de monjes, principalmente benedictinos, cuyo 


\section{El inicio pastoral de Gonzalo como párroco}

Sus biografías -después de ordenados- fueron realmente distintas. Domingo inició una vida regular como canónigo con profesión de votos religiosos bajo una regla y vida comunitarias, Amarante asumió la vida propia de clérigo secular, volcada a la atención pastoral de su feligresía. No obstante, en lo hagiográfico no hay mayores distinciones, santo Domingo "brillaba entre los canónigos con resplandor extraordinario", y Gonzalo propagaba "todas las luces que deben adornar a un pastor según el corazón de Dios" ${ }^{20}$. En ambos, las luces y el brillo consistían en ser humildes de corazón, austeros en la vida y entregados a la oración para seguir a Cristo. Actitudes que en los dos culminaban con el don de lágrimas, en el fundador de los dominicos manifestado cuando lloraba "por los pecadores, por los desdichados y por los afligidos", y en el portugués para: "que por intercesión" de la Virgen María, Dios "le diera su gracia y sabiduría para gobernar [a] sus ovejas"21.

En 1203, Domingo acompaña a su obispo a las Marcas -la actual Dinamarcae inicia el periplo de los antecedentes de la fundación de su Orden por las actuales naciones de Francia, Bélgica, Holanda, el norte de Alemania y gran parte de Italia (Galmés, 1987, p. 52). Por su parte, Amarante solo trabajó en Portugal, un reino en franca expansión sobre los antiguos territorios musulmanes del sur, especialmente durante el reinado de Alfonso III (1248-1279), quien conquistó el Algarve, reforzó la autoridad real y aseguró la existencia de una progresiva estructura administrativa. En lo eclesiástico, Portugal, al igual que el resto de Europa Occidental, atestiguó la consolidación de las parroquias como unidades administrativas, independientes de los señoríos feudales en cuanto a su jurisdicción territorial y la atención sacramental a su feligresía, a partir de una sede o curato atendido por un presbítero solo dependiente del obispo ${ }^{22}$.

gobierno dependía de un abad; además de poseer importantes posesiones de tierras, ejercer un señorío sobre las aldeas ubicadas en sus dominios y albergar una escuela para educar a los hijos de los señores. En el caso de Amarante, el título de abad era honorífico, tenía atribuciones parroquiales y gozaba del beneficio de rentas.

20 Para Santo Domingo en Galmés, 1987: Sajonia, núm. 11, p. 87; Romans, núm. 8, pp. 298-299; Cerrato, núm. 5, pp. 339-340; para Gonzalo: Amado, 1829, p. 5; Croiset, 1842, p. 156; Álvarez, 1920, pp. 221-222.

21 Para Santo Domingo en Galmés, 1987: Jordán, núm. 12, p. 87; Romans, núm. 8, p. 299; Cerrato, núm. 5, p. 340; para Gonzalo: Bordazar, 1739, p. 7; Álvarez, 1920, p. 221.

22 De los hagiógrafos solo Álvarez indica que los beneficios eclesiásticos fueron una parroquia y una abadía de iglesia, 1920, p. 221. Amado señala una parroquia, 1829 p. 5 y Croiset una abadía, 1842, p. 156. 


\section{El peregrinaje de Gonzalo a Tierra Santa: el llamado de la voz}

En la parroquia de San Pelagio de Riba de Visela, Gonzalo tuvo un llamado interior, el irse de peregrino. Los autores lo explican como: la escucha de una voz interior, el resultado de sus continuas meditaciones y oraciones o, sencillamente, por su devoción personal a la Pasión de Cristo y deseos de visitar la Tierra San$\mathrm{ta}^{23}$. Es notorio que en la vida de santo Domingo no haya referencias a esa voz interior, pero sí se le encuentra y en gran número en la tradición bíblica canónica. Por ejemplo en el Antiguo Testamento, Dios habla sin nunca ser visto por los hombres: Adán y Eva después de comer del fruto prohibido, son duramente cuestionados por Dios (Gn 3,8); Moisés luego de realizar las ofrendas de las carretas, conversa con Dios en la carpa (Nm 7,89); Isaías fue invitado a ser profeta por Dios y luego lo envía a emprender su nueva vida (Is 6,8); el pueblo de Israel es amorosamente consolado por Dios con su liberación, durante su cautiverio en Babilonia (Is 40,3-6); y a los defraudadores y saqueadores de su pueblo elegido, Dios los increpa con dureza (Mi 6,9-25). En el Nuevo Testamento, Dios proclama desde el cielo con voz sonora la divinidad de su Hijo, esto al concluir su bautizo en el río Jordán y en el momento culminante de su transfiguración sobre el monte (Mc 1,11; Lc 3,22; Mt 15,5; Mc 9,7; Lc 9,36; Jn 12,28). También al apóstol Pedro, una voz le dijo en dos ocasiones: "Levántate, Pedro, sacrifica y come” (Hech 10,13; 11,7).

En la tradición apócrifa popular, Dios igualmente se revela mediante una voz celeste dirigida a los recién convertidos al cristianismo, aunque con una diferencia abismal: que ellos después de ser ungidos o bautizados contemplarían a Dios, pero no cara a cara, sino por ejemplo a través de un joven que porta una lámpara cuya luz opacará a todas las antorchas llevadas por los presentes ${ }^{24}$.

En la tradición hagiográfica antigua -como en la bíblica y en la apócrifa popular-, Dios también habla mediante sus ángeles, quienes pueden transmitir mensajes tan inocentes y ocurrentes como el recibido por el romano Sabiano, quien después de leer un salmo se inquietó por no entender el significado de las palabras: "Rocíame Señor con tu hisopo y quedaré limpio..." (51 [50], 9). En este caso las palabras angélicas

23 Respectivamente: Amado, 1829, p. 5; Croiset, 1842, p. 157; Álvarez, 1920, p. 222. Bordazar remarca su devoción a la pasión de Cristo y el discernimiento de lo presente como un proceso, 1739 , pp. 9-10.

24 En Piñero y del Cerro, 2005, “Hechos de Tomás”, v. II, núm. 27, 1-3, pp. 953-957; núm. 121,3 , p. 1125. 
fueron: "No te aflijas [Sabiano] de esa manera; no te dejes llevar de la desesperación ni [d]el deseo de morir; cuando te bautices quedarás más blanco que la nieve; entonces entenderás lo que ahora no entiendes" (Vorágine, 2001, v. 2, p. 556).

A su vez, san Timoteo se encontraba en una situación realmente mucho más apurada que la de san Sabiano, pues durante su martirio, "cuando [le] estaban arrojando cal viva sobre sus heridas [...], se le aparecieron dos ángeles y le dijeron: alza tus ojos y mira hacia el cielo" y Timoteo, vio que "las puertas de la gloria estaban abiertas para él" y Cristo con los brazos extendidos lo invitaba a entrar (Vorágine, 2001, p. 522).

\section{La partida de Portugal}

Gonzalo, después de escuchar esa voz interior y con el permiso de su arzobispo, dejó como su vicario parroquial "a un sobrino suyo, sacerdote, que había criado desde la infancia". El cura le encomendó "mucho la conducta que había de tener con los feligreses", y "tomó el hábito y bordón de peregrino y partió" (Bordazar, 1739 , pp. 10-12) ${ }^{25}$. Iba con un jubón humilde, signo de su revestimiento como peregrino, y portaba una cruz de madera en el pecho como señal de su viaje al sepulcro de Cristo. Así llegó a Roma, donde oró ante las tumbas de los apóstoles Pedro y Pablo, para luego zarpar rumbo a Palestina.

Su estancia duró 14 años, tiempo en que no le faltaron incomodidades ni sudores y su don de lágrimas afloró, "como si verdaderamente" hubiese hallado a "Cristo en persona y le tratara y adorara" (Bordazar, 1739, pp. 12-14)26. Esta búsqueda de Amarante fue compartida por miles de cristianos europeos durante el siglo XIII. Por ejemplo, en el caso de los dominicos, los primeros religiosos llegaron a Palestina en 1225, en concreto a los territorios ocupados por los cruzados.

En 1228, el capítulo general de la Orden creó la provincia de Tierra Santa con la tarea de difundir el cristianismo latino en el Medio Oriente y sus alrededores. Los frailes lograron entablar relaciones con las comunidades orientales de jacobitas, nestorianos, georgianos, maronitas, griegos y armenios, hasta que en 1291

25 Amado, 1829, p. 5; Croiset, 1842, p. 157; Álvarez, 1920, p. 222.

26 Los autores no señalan fechas, Álvarez, 1920, p. 222; Amado, 1829, p. 5; Croiset, 1842, p. 157. 
desapareció la provincia debido a la conquista musulmana de San Juan de Acre (Mandonnet, 1929, pp. 103, 104, 157-158)27.

\section{La vuelta a la patria}

Como con otras fechas, se desconoce el año del retorno de Gonzalo a Portugal, pero se sabe que volvió "enfermo y debilitado del trabajo de andar a pie, pálido, macilento del hambre y penitencias: de ropa no poco lucido, más en parte mal remendado [...], el rostro quemado y denegrido, el cabello cano y descompuesto" (Álvarez, 1920, pp. 222-223). Al llegar a la parroquia de San Pelagio, "se sentó a descansar en la puerta de la iglesia, y a la hora de comer llegó a la casa de su sobrino a pedir limosna" (Bordazar, 1739, pp. 15-17) ${ }^{28}$. De acuerdo con sus hagiógrafos, Gonzalo -como buen peregrino- no solo regresó transformado en lo físico, sino también en lo espiritual (Bordazar, 1739, p. 16) ${ }^{29}$. Llegó como otro Lázaro, el mendigo (Lc 16,19-21). Ambos comparten actitudes similares: sufrieron hambre, pidieron limosna y fueron rechazados, los dos tocaron para suplicar comida a personajes acaudalados.

Lázaro a "un hombre rico que vestía de púrpura y lino, y celebraba todos los días espléndidas fiestas", Gonzalo a su sobrino que a costa de los pobres vivía lujosamente y que además había malversado las rentas de la parroquia, destinadas para aliviar a los pobres (Amado, 1829, p. 5) ${ }^{30}$. A Lázaro nunca le abrieron la puerta y antes de morir tuvo que conformarse con las lamidas de los perros sobre sus llagas de leproso; a Gonzalo le dijeron: "que allí no se daba limosna a semejantes personas" (Bordazar, 1739, p. 17). Pero pudo enviar un mensaje a su sobrino donde le decía, "quién era y que mirase que no era aquello lo que [él] le

27 Del patriarcado jacobita dependían cristianos caldeos, persas, medos y armenios. Según la tradición, en 1237 fue famosa la abjuración de su patriarca que por la predicación del padre Felipe, abjuró a su herejía y tomó el hábito de dominico, Tourón, 1826, pp. 345-346.

28 Bordazar afirma que el sobrino "fingió cartas y buscó testigos falsos, que juraran ser muerto el tío. Y mediado el parentesco y virtud del que se suponía, aunque falsamente, difunto, fue provisto de la iglesia".

29 Amado, 1829, p. 5; Butler, 1968, p. 112; Álvarez, 1920, pp. 222-223.

30 Bordazar afirma que el sobrino "se trataba como príncipe: muchos criados, mesa espléndida, caballos, azores y perros de caza consumían los frutos de la iglesia de San Pelayo", 1739 , pp. 15, 17. 
había prometido hacer con los pobres al tiempo de su partida". La reacción del vicario fue salir y:

Con un bastón le dio de palos. Sufriólo el Viejo con grande paciencia y díjole: ¿Esta es la crianza que yo te di? ¿Así se gasta la hacienda que te dejé? ¿Esta misericordia hallan los pobres en esta casa?

El sobrino respondió embravecido y como un demonio echóle los perros, que le mordieron, y amenazóle con que le molería a palos si no se iba inmediatamente ${ }^{31}$.

\section{El retiro}

A diferencia de Lázaro, Gonzalo murió únicamente para su vida anterior, la de párroco con importantes rentas. A la manera de los primeros ermitaños, el lusitano partió al desierto para "amar a Dios, y [...] persuadir a los hombres [acerca de] las saludables verdades de la Religión"; para predicar y reparar "las faltas de su sobrino" y las propias (Amado, 1829, p. 5) 32 . En esta sexta etapa de su vida, Croiset afirma que "vivió como otro Pablo e Hilarión en el desierto, contemplando y predicando" (1842, p. 157). La mención en su vida de estos ermitaños es capital, porque no solo lo enlaza con las raíces de la vida religiosa, sino también legitima su lugar dentro de esta tradición y ello, permitirá a los autores incorporar a su hagiografía algunas novedades, como más adelante se verá.

La Vita Pauli - La vida de Pablo- fue escrita por san Jerónimo en torno al año 375, en el desierto sirio de Calcis. Casi diez siglos después, fray Santiago de la Vorágine la resumiría en su Leyenda dorada, de allí su muy amplia difusión a partir del siglo XIII (Vogüé, 1991, pp. 150-184)33. Lo mismo ocurrió con Hilarión, sobre el cual san Jerónimo redactó su Vita Hilarionis -La vida de Hilarión- antes del 393

31 Amado, 1829, p. 5. Bordazar consignó que el sobrino le dijo: que él no "mantenía vagabundos, que por no querer maltratar el cuerpo con pequeño trabajo, querían vivir a costa ajena", 1739. 2, pp. 17-19.

32 Croiset, 1842, p. 157. Bordazar contrasta este desconocimiento con la recepción que tuvo el mendigo Alejo, al volver accidentalmente a su patria y ser descubierto por su familia, 1739, p. 19. La vida de Alejo en Vorágine, t. 1, 2001, pp. 378-382.

33 Vorágine, t. 1, 2001, pp. 97-99. 
y siendo también de la Vorágine quien la popularizaría (Rivas, 1994, pp. 226268). Como en la hagiografía de Amarante, La vida de Pablo no es una biografía completa -solo es una aproximación al inicio y término de su vida monacal-, y es significativo que su trama sea paralela a La vida de Antonio redactada por san Atanasio -otra figura paradigmática del monacato cristiano-, escrita aproximadamente en el año 356.

En este sentido, Gonzalo como san Pablo inició su desierto o retiro despojado de bienes para poder seguir a Cristo desnudo y humillado, para iniciar una nueva vida después de los abusos cometidos por su sobrino. Pablo lo hizo para conservar la fe cristiana y su castidad personal, amenazadas a raíz de las persecuciones desatadas contra los cristianos por los emperadores romanos Decio (249) y Valeriano (257) (Migne, 1884, 23, 17-30, párrafos 2-3).

En épocas muy distantes, tanto Pablo como Gonzalo concibieron su retiro como un combate por Cristo. Pablo, para vivir en el desierto las virtudes de la fe -teologal-y la castidad -cardinal-; Gonzalo, para vivir una pobreza radical y predicar el Evangelio, durante el siglo del nacimiento de las órdenes mendicantes. Pablo en el siglo III frente a un Imperio romano en plena crisis estructural y Gonzalo en el siglo XIII, con sus transformaciones comerciales y urbanas.

Estas notorias diferencias entre sus épocas también aparecen en sus estilos de vida. Pablo "vivía exclusivamente de pan de cebada y de agua cenagosa, en completa soledad y alejado de todo trato humano durante 60 años" (Vorágine, 2001, t. 1, p. 97) ${ }^{34}$. En contraste, Gonzalo dependía de las limosnas y no rehuía el trato con la gente, al contrario, su propósito de predicar el Evangelio le hacía ir a su encuentro. Otra diferencia es que Amarante, con las limosnas recibidas, "remediaba las necesidades de muchos pobres" y construyó "una pequeña ermita dedicada a la Santísima Virgen", así, le "rendía a la Reina de los Ángeles un culto filial" (Bordazar, 1739, p. 21) 35 . Con una decena de siglos de por medio, es notoria la sistematización del ejercicio de la caridad cristiana y la popularidad de las devociones marianas en el siglo XIII. Aun cuando en los primeros siglos del cristianismo, la vida religiosa -todavía en formación- únicamente era cristológica, en la Edad Media aparece llena de devociones marianas y de santos, sin que ello

34 San Jerónimo escribió que durante los primeros 37 años de ermitaño, Pablo comía dátiles, producidos por una palma que se encontraba en su cueva, después un cuervo le daba de comer medio pan, Migne, núm. 6.

35 Croiset, 1842, p. 157; Amado, 1829, p. 5. 
signifique que el seguimiento de Cristo fuera secundario. Al respecto, B. Calatabí explica de manera breve el cristocentrismo de la hagiografía medieval:

La hagiografía medieval tiene la preocupación de demostrar cómo se vive la Sagrada Escritura para terminarla y complementarla. El santo, en la mente del hagiógrafo medieval, sobre todo del santo monje, es aquel que realiza plenamente la economía divina, según el trazado histórico de la Biblia. Toda la trama general de cada "vita" obedece a esta idea: se trata de poner en evidencia cómo el hombre, creado por Dios y puesto en el paraíso histórico de la Biblia, expulsado por el pecado, debe retornar por la gracia de Cristo (1957, pp. 3-7).

Gonzalo de Amarante nunca fue monje ni pretendió serlo, hasta este momento era un cura secular en retiro, en oración, volcado a la predicación y a la caridad desde una ermita consagrada a María. En cuanto a la tradición monástica primitiva, de la Vorágine subraya que "Pablo fue el primer ermitaño". Su fuente es sin duda san Jerónimo, quien en su Vita Pauli describe un sueño tenido por Antonio a los 90 años de edad. En ese sueño, Dios le revela a Antonio la existencia de un ermitaño más perfecto que él: Pablo que vive "más adentro del desierto" y tiene más años que él por lo que le ordena visitarlo.

En el camino -según san Atanasio, quien escribió su vida-, el monje egipcio se topa con seres míticos y animales que lo atacan porque son instrumentos del demonio $^{36}$. En contraste, en la historia de Pablo sucede lo contrario, pues tales seres además de ayudarlo a encontrar la cueva del viejo ermitaño, le hablan de Dios y le piden oraciones; siendo ya estos seres parte de un mundo cristianizado ${ }^{37}$. En la selva, primero un hipocentauro le señaló con una de sus patas la dirección a seguir (Vorágine, 2001, t. 1, p. 98) ${ }^{38}$. Luego un sátiro le confiesa que "los paganos erróneamente" lo consideran "rey de la selva" y le pide que ore por todos ellos

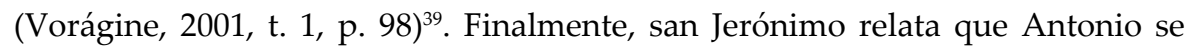

36 Atanasio, 1995, núm. 50, 9, pp. 85-86, núm. 52, 2-4, p. 87.

37 Migne, 1884, v. 23, núms. 7-8.

38 La cabeza, cuello, brazos y manos de los hipocentauros eran de hombres, el resto del cuerpo de caballo. Eran diestros arqueros y maceros, su voz eran relinchos, Chompre, 1783, pp. 94, $147-148$.

39 Los sátiros eran "medio hombres y medio cabras, con cuernos", vivían en los bosques y eran honrados como a dioses, Chompre, 1783, p. 477. 
encontró con una zorra, la cual le indica la señal final para encontrar el refugio de Pablo. Es de especial interés que haya sido precisamente una zorra, un animal que pasó al cristianismo como símbolo demoníaco, la que le muestre el camino, lo que significa el triunfo de Antonio y Pablo, por la gracia de Cristo, sobre los engaños del demonio o tentador ${ }^{40}$.

\section{Una pregunta de Gonzalo y su respuesta celestial}

El camino de perfección para Gonzalo no se encontraba en la vida eremítica. Sus hagiógrafos mencionan la presencia de una insatisfacción o turbación debida a su fama de santidad que le hizo preguntarse: “Si aquella manera de vivir agradaba a Nuestro Señor y a su Madre?" (Bordazar, 1739, pp. 22-23) ${ }^{41}$. Después de largos ayunos y oraciones, obtuvo la respuesta mediante una visión, la historia es la siguiente: una noche, frente al altar de la Virgen, en su ermita "oyó una voz que le dijo: levanta, siervo mío, y sigue entre las órdenes religiosas esparcidas por el mundo, al que oyeres que da principio y fin a los oficios divinos con la salutación angélica" (Croiset, 1842, pp. 157-158) ${ }^{42}$.

En conclusión, Gonzalo fue llamado para hacerse fraile y la invitación tiene relación con los pasajes de Mateo y Lucas, donde Jesús estuvo "cuarenta días y cuarenta noches" en ayuno para después ser tentado por el diablo y vencedor, iniciar su misión mesiánica (Mt 4,1-11 y Lc 4,1-13). A diferencia de Jesús, Amarante no fue tentado sino turbado, debido a las alabanzas que su fama de santidad le acarreó entre "muchos personajes portugueses" (Croiset, 1842, p. 157). A san Hilarión le ocurrió algo muy parecido, cuya vida austera y santa atraían a multitudes en búsqueda de ayuda y curaciones, entre ellos "acudían obispos, presbíteros, clérigos y monjes" (Migne, 1884, v. 23, núms. 21, 37) ${ }^{43}$.

40 La conducta de la zorra está relacionada con las mentiras y la hipocresía, representa las obras de la carne descritas en Gálatas (5,19-21), Fisiólogo, 2008, núm. 15, p. 164; de la Vorágine menciona a un lobo, 2001, p. 8.

41 Villegas, 1615, p. 398; Amado, 1829, p. 5; Croiset, 1842, p. 157; Álvarez, 1920, p. 223.

42 Álvarez también ubica la visión en la ermita, solo que fue una fuerte luz la que lo despertó e iluminó la capilla, por lo que pudo ver a la Virgen quien le dijo lo mismo, agregando la instrucción de que tomara el hábito en esa orden religiosa, 1920, p. 223. Amado y Butler omiten el contexto, respectivamente en 1829, p. 5 y 1968, p. 112.

43 Asimismo Rivas, 1994, pp. 226-268; Vogüe, v. 2, 1993, pp. 163-236; Bastiaensen, t. 4, 1975, pp. 69-143. 


\section{La búsqueda y el encuentro}

Después de interpretar la visión tenida en la ermita como un mandato del Cielo, el lusitano tomó camino para buscar a esa orden religiosa. La encontró en el convento de Santo Domingo en Guimarães, donde de acuerdo con la tradición su prior era san Pedro Telmo González (Bordazar, 1739, pp. 23-24) ${ }^{44}$. Ahí constató que todos los días, los frailes iniciaban el canto de maitines con la salutación angélica: Angelus Domini nuntiavit Mariae... -“El Ángel del Señor anunció a María..."- y concluían la oración de completas con el canto de: Salve Regina Mater misericordiae... - "Salve Reina y Madre de misericordia..."-, por lo que pidió el hábito de los dominicos (Bordazar, 1739, p. 24) ${ }^{45}$.

En conclusión, su llamado culminó con la vestición del hábito de dominico: la Virgen "le vistió pues, [y Gonzalo] profesó el instituto" (Amado, 1829, p. 5) ${ }^{46}$. Pero esta característica tampoco es original de Amarante, porque antes que él dos frailes famosos fueron llamados por María para tomar el hábito de la Orden de Predicadores. El primero fue el maestro Reginaldo que, estando "con fiebre altísima" ella lo visitó, lo ungió y "luego mostrándole el hábito de los Predicadores, le dijo [...]: este es el hábito de tu Orden" ${ }^{\prime 7}$. El segundo fue fray Enrique, quien concluyó: “Esta es mi Señora, la madre del Salvador, que me ha elegido para su servicio" ${ }^{\prime 48}$.

En otra escala los hagiógrafos, a partir de la invitación hecha por la Virgen, resaltan que la Orden de Predicadores no solo le profesaba una veneración especial a María, sino que la madre de Dios era su protectora y le dispensaba "muchas mercedes y favores". Lo último se hace manifiesto cuando "la Señora le dijo [a

44 Guimarães se ubica en la provincia portuguesa del Miño, en la diócesis de Oporto. Los primeros conventos dominicos portugueses fueron el de Oporto (1237) y el de Lisboa (1242), Álvarez, 1920, pp. 137, 141-142. La provincia dominicana de Portugal es tardía, fue fundada en 1488, antes pertenecía a la provincia de Castilla o de España, fundada en 1221. En 1288, fue dividida en dos: en la nueva provincia del Reino de Aragón (Aragón, Cataluña y Valencia) y la de España integrada por Portugal, Castilla, León y Galicia, Madonnet, 1929, pp. 149-150.

45 Álvarez, 1920, pp. 223-224; Croiset, 1842, p. 158; Butler, 1968, p. 112.

46 Villegas, 1615, p. 398. En algún momento se dudó de la pertenencia de Amarante a la Orden de Predicadores, incluso se le representaba como cura secular, Bordazar señala una sentencia de la Sagrada Rota, del 11 de abril de 1615, donde se despejan las dudas, 1739, pp. 24-25.

47 En Galmés, 1987, Sajonia, núm. 57, p. 102. Se repite en: Ferrando, núm. 35, p. 236; Romans, núm. 35, p. 311 y Cerrato, núm. 16, pp. 346-347.

48 En Galmés, 1987, Sajonia, núm. 83, p. 112. 
Gonzalo] que debía vestir el hábito de los Predicadores, pues su Hijo le llamaba a esta sagrada Orden" (Amado, 1829, p. 5) ${ }^{49}$. La hagiografía del siglo XIII de santo Domingo y en general de su Orden, están fuertemente permeadas por la mariología medieval.

Por ejemplo, la costumbre de cantar la salve al concluir el rezo de las completas, proviene -según la tradición- del convento de Bolonia, en Italia, práctica que se remonta a los primeros años de la Orden ${ }^{50}$. Además, el propio fundador tuvo varias visiones donde la Virgen le manifestaba su patrocinio e incluso, en algún momento escuchó la voz de Jesús que le dijo: “Tu Orden la he encomendado a mi Madre", por lo que se puede interpretar hagiográficamente que este patrocinio mariano fue por voluntad del propio Jesucristo ${ }^{51}$. Se trata de una relación recíproca, donde María asume un patrocinio o protección corporativa y la Orden le corresponde con fervor y alabanzas al iniciar y finalizar la jornada. A partir del siglo XIV se sumaría el rezo del rosario como la expresión mariana por excelencia de los dominicos.

\section{La vida como fraile}

Al concluir el noviciado, Gonzalo profesó sus votos como fraile predicador y fue enviado a Amarante para que predicara: "a esos pueblos que ya conocían su voz y su santidad, la doctrina de la salud" (Bordazar, 1739, p. 25) ${ }^{52}$. Aunque a simple vista, la vida del nuevo dominico no parece haber cambiado, pues volvió a su ermita, en realidad sí cambió y mucho. Primero, porque ahora fue mandado por una comunidad, el convento de Guimarães, donde el prior y el capítulo conventual personificaban la tarea encomendada por Jesús a los apóstoles de ir a

\section{9 Álvarez, 1920, p. 223.}

50 En Galmés, 1987, Jordán de Sajonia, núm. 120, pp. 122-123. Afirman lo mismo: Cecilia Romana, núm. 7, p. 674; Cerrato, núm. 48, p. 362 y Gerardo de Frachet, cap. 7, núm. 1, pp. 410-411.

51 Plásticamente se representa a María en su Patrocinio, cubriendo con su manto a los frailes dominicos, porque así fue la visión del santo fundador. En la primera visión aparece María acompañada por santa Cecilia y santa Catalina, en Galmés, 1987, Cecilia Romana, p. 661, núm. 7, pp. 673-674. Rodrigo Cerrato afirma que fue santo Domingo el que encomendó el cuidado de su Orden a la Virgen María, "como a su patrona especial", núm. 48, pp. 361-362.

52 Amado, 1829, p. 5; Croiset, 1842, p. 158. Álvarez señala al fraile compañero, 1920, p. 224 y Butler afirma que fray Gonzalo tuvo permiso para "vivir como ermitaño", 1968, p. 112. 
predicar el Evangelio (Mt 10,5-15. 28,19-20; Mc 6,7-13. 16,15-16) ${ }^{53}$. Segundo, tal y como aparece en el Evangelio de Marcos $(6,7)$, Gonzalo fue enviado en compañía de otro fraile: “Y [Jesús] llama a los Doce y comenzó a enviarlos de dos en dos... "54. Tercero, porque los pueblos de Amarante "ya conocían su voz y santidad", expresión con clara alusión al Evangelio de Juan $(10,4)$ “y las ovejas le siguen, porque conocen su voz" (Bordazar, 1739, p. 25).

Alineado con los pasajes evangélicos, donde las multitudes seguían a Jesús (Lc 2,13; Jn 6,2), Manuel Amado escribe que, "las gentes corrían en tropas a escuchar la doctrina de su apóstol [Gonzalo], y las turbas que venían a oírle se hacían cada vez más numerosas". Y agrega que "de todo sacaba partido, a todos hablaba al corazón, y en todos causaba efecto su predicación, apoyada con la austeridad de su vida, y con la multitud de sus milagros" (1829, pp.5-6). Su fama se extendía por la región (Lc4,14) (1829, p. 5); las conversiones se multiplicaban (Mt 4,17; Mc 1,15. 6,12) $(1829, \text { p. } 5)^{55}$ a ejemplo de Jesús y al modo de santo Domingo de Guzmán ${ }^{56}$.

\section{Los milagros de fray Gonzalo}

Dos son sus milagros más famosos, la construcción de un puente y la conversión de un grupo de incrédulos. El primero fue porque "el paso del río Tamaga ofrecía mil peligros" al gentío que acudía a escuchar su predicación (Croiset, 1842 , p. 158) ${ }^{57}$. Por ello, Gonzalo determinó construir un puente. Bordazar sostiene que tal proyecto: "para muchos pueblos juntos fuera de grande peso, y para un rey parecería muy costosa, cuanto más para un pobre religioso, que de suyo no tenía más que el breviario en que rezaba" (1739, p. 26). Amado agrega que la obra fue sin "ningún recurso humano, [porque] contaba bastante con la Providencia” (1829, p. 5).

53 Según las Constituciones de 1228, para predicar bastaba la "licencia y mandato" del prior, en Galmés, 1987, núm. 20, p. 758. Solo en el plano electoral, la dependencia al convento era mediante su participación en los capítulos electivos para votar por: el prior, el compañero del prior para el capítulo provincial y para definidor al capítulo general, distinción segunda, núms. 1, 7, 24, pp. 749, 751, 760 .

54 Bordazar menciona que su compañero fue "fray Lorenzo Méndez, varón santísimo y esclarecido en virtudes y milagros, como también fábricas de puentes", 1739, p. 25.

55 Álvarez, 1920, p. 224.

56 En Galmés, 1987, Orvieto, núm. 51, p. 269; Romans, núm. 53, p. 320.

57 Villegas, 1615, p. 398; Amado, 1829, p. 5; Álvarez, 1920, p. 224. 
Croiset y Álvarez son más realistas al afirmar que la ejecución del proyecto fue "con limosnas que recogió de los pueblos comarcanos, y en su construcción se refieren varios milagros" (1842, p. 158 y 1920, p. 224). Butler también fue cauto al escribir que la edificación fue "casi sin ayuda" (1968, p. 112). De cualquier forma, la obtención del dinero no estuvo exenta de milagros, pues cuando el fraile estaba pidiendo limosna, se topó con un matrimonio rico y ante su súplica, el marido le extendió una libranza donde escribió: “Daréis a este fraile inocente para su puente tanto dinero, cuanto pesare este papel". Y cual fue la enorme sorpresa que al pesar el papel, "éste parecía de plomo y el santo recibió mucho dinero para la construcción del puente" (Bordazar, 1739, pp. 32-33).

Otro milagro consistió en la elección del lugar para la edificación del puente. Un ángel le indicó que fuera cerca de la ermita, pero contra todo sentido común debido a lo fragoso del terreno, ubicado "entre dos peñascos que están a ambos lados del río [Tamaga]". Los milagros se prolongaron durante todo el proceso de construcción, fray Gonzalo era "uno de los que más trabajaba, llevando y trayendo piedras que muchos hombres juntos no podían moverlas" (Bordazar, 1739, pp. 29, 31-32 $)^{58}$. Así mismo, para conseguir bestias de carga, el dominico se encaminó al monte donde, "unos bueyes salvajes recibieron el yugo como mansos corderos y los toros jalaron las carretas con piedras muy pesadas, por un camino tan accidentado que marcaron sus huellas y estas se conocen como las ruedas de Marañon" (Bordazar, 1739, pp. 33-35) ${ }^{59}$.

En su preocupación por la falta de vino para los trabajadores, fray Gonzalo "subió a lo alto de la sierra, junto a su ermita, y se puso de rodillas en oración sobre una grande peña, suplicando al Señor que le diese de beber para su gente a fin de que no desmayasen" (Bordazar, 1739, p. 36) ${ }^{60}$. Ahí, como Moisés frente a la roca del Horeb (Ex 17,5-6), el portugués "dando un golpe en la peña con su cayado, invocando el dulce y poderoso nombre de Jesús, salió de la peña, por un agujero que en ella se abrió gran cantidad de excelente vino" (Bordazar, 1739, pp. 36-37) ${ }^{61}$. Esto lo repetía tres veces al día "para acompañar las tres comidas" de los operarios (Villegas, 1615, p. 37). De igual forma procedía ante la falta de agua, pero en otra peña de donde brotó un cauce "de agua dulce, clara

\footnotetext{
58 Amado, 1829, p. 224.

59 Acerca de "las ruedas de Marañón" no se encontró información.

60 Álvarez, 1920, p. 224; Butler, 1968, p. 112 y Amado, 1829, p. 5.

61 Álvarez, 1920, p. 224.
} 
y saludable, bien diferente de la del río" (Bordazar, 1739, p. 38) ${ }^{62}$. Aquí Gonzalo es presentado como un nuevo Moisés para su pueblo, nuevo porque trasciende a la antigua ley por predicar el Evangelio y realizar milagros solo por la gracia de Cristo, quien como Mesías e Hijo de Dios es mucho más que el Moisés del Antiguo Testamento, aunque ambos subieran a las cimas de las montañas para hablar con Dios (Ex 19,20-22).

Santo Domingo de Guzmán, "en el nombre del Señor" y trazando la señal de la cruz, atravesaba ríos crecidos, alejaba lluvias torrenciales, expulsaba demonios y curaba enfermos ${ }^{63}$. Multiplicaba el vino, pero al modo de las bodas de Caná (Jn 2,3-11), donde Jesús convirtió el agua vertida en unas tinajas en buen vino. Santo Domingo lo hizo varias veces: de camino a Toulouse en compañía de ochos frailes; en Bolonia con el vino destinado a los religiosos enfermos; y en Roma frente a 25 frailes y la comunidad de monjas de San Sixto ${ }^{64}$. Los milagros de la multiplicación del vino también son recurrentes en la hagiografía antigua, por ejemplo, san Remigio "hizo la señal de la cruz sobre una de las tinajas [vacías], oró, y al momento la tinaja se llenó hasta el borde y de ella siguió fluyendo vino en tal abundancia que rebasó la capacidad de la vasija y se derramó por el pavimento" (Vorágine, 2001, t. 1, p. 99).

Las multiplicaciones no solo comprendieron al vino y el agua, sino también al pan y a muchos pescados, alimentos indispensables en el sur de Europa. Su fundamento bíblico está en los evangelios sinópticos, donde Jesús da de comer a miles de personas (Mt 14,13-21. 15,32-39; Mc 6,30-34. 8,1-10; Lc 9,10-17). En el milagro de Amarante lo más novedoso se encuentra en el comportamiento que tuvieron los peces, ya que después de que el fraile hiciera la señal de la cruz sobre el río, aparecieron peces a "montones" que se lanzaban a la orilla, "uno sobre otro con tanta prisa, que parecía quererle todos besarle los pies", pero el santo únicamente tomaba los necesarios y los otros "eran despedidos con otra bendición" (Bordazar, 1739, p. 39).

En el evangelio apócrifo del Pseudo Tomás, hay un relato similar donde el Niño Jesús para llamar la atención de otros infantes, “cogió un pez disecado, lo

62 Álvarez, 1920, p. 224.

63 En Galmés, 1987, “Actas de los testigos de Bolonia”, testigo IV, núm. 2, p. 156; Sajonia, núm. 101, p. 117; núm. 126, p. 126; Romans, núm. 45, p. 317; Romana, núm. 1, p. 664; núm. 2, p. 666; núm. 5, p. 670.

64 En Galmés, 1987, Cerrato, núm. 23, pp. 349-350; Frachet, I parte, núm. 2, p. 387, II parte, núm. 5, p. 417; Romana, núm. 6, pp. 671-672, entre otros ejemplos. 
echó en una jofaina y le mandó que empezara a colear: ¡Anda, arroja la sal y échate al agua!"' Y así ocurrió (Santos, 1963, núms. 3-4, p. 304). En consecuencia, gracias a los milagros que Dios obró mediante el santo, el tiempo de construcción fue más rápido de lo esperado (Bordazar, 1739, p. 31) ${ }^{65}$. Su propósito inmediato era favorecer la construcción y alimentar "abundantemente a los obreros", evitando por ejemplo que por falta de vino los operarios "dejasen de trabajar" (Amado, 1829 , p. 5) ${ }^{66}$. No obstante, la intención de fondo de todos los milagros es subrayar el seguimiento de Cristo por parte de Amarante.

El segundo milagro famoso ocurrió en una controversia doctrinal con un grupo de incrédulos, rayanos en la herejía, una tendencia muy común en el siglo XIII, representada sobre todo por los cátaros y los albigenses, respectivamente en el sur de Francia y el norte de Italia. El reto de Amarante fue probar materialmente la eficacia del poder concedido por Cristo a Pedro y por tanto, a la Iglesia "para atar y desatar", es decir, para perdonar o no perdonar los pecados de acuerdo al arrepentimiento del infractor (Mt 16,19). En sus correrías, fray Gonzalo se encontró con un grupo de personas que:

Menospreciaban la pena de la excomunión diciendo que no quebrantaba los huesos, que no tenía ninguna importancia. Pero en ese momento, pasaba una mujer con una cesta de pan bien blanco y regalado; y como el santo vio, le dijo que se llegase allí cerca y descargase el pan para que se viese cuán hermoso era. Hízolo así la mujer y el santo dijo al pueblo: Yo fray Gonzalo, de parte de Dios, y de la Santa Madre Iglesia Católica Romana, descomulgo, y tengo por descomulgado este pan. Dicho esto, se volvió el pan más negro que el carbón [...]. Lo mismo hace en el alma la excomunión, y muy más fea la pone y más abominable. Luego para que vieran cuánto bien le viene a la persona a quien se absuelve de la excomunión, pidió agua bendita y con ella roció los panes diciendo que los absolvía, y recobraron los panes su primera calidad. Lo que convenció y asustó a esa gente ruda (Bordazar, 1739, p. 41) ${ }^{67}$.

Este milagro está conectado con otro realizado por santo Domingo. En él, el fundador también se encontraba en una controversia, donde la prueba final

65 Álvarez, 1920, p. 224.

66 Ver (Butler, 1968, p. 112).

67 Álvarez, 1920, p. 256; Amado, 1829, p. 6; Butler, 1968, p. 112. 
consistía en arrojar varias veces al fuego un libro, donde estaba escrita "la confirmación de la verdadera fe [y este libro] no solo resultó ileso [de las llamas], sino que, a la vista de todos, saltó del fuego yendo a parar a un lugar distante". En cambio, "el libro de los herejes se quemó al momento" (Galmés, Gómez, 1987, p. 92). Este milagro recuerda el sacrificio realizado por el profeta Elías en el monte Carmelo (1R 18,20-40), pero en sentido inverso, es decir que la prueba fehaciente de veracidad consistía precisamente en arder, en ser presa del fuego. En el caso de la Orden de Predicadores, las herejías fueron la realidad que en santo Domingo ocasionaron una gran inquietud para acudir a los herejes, predicar el Evangelio, dar testimonio de pobreza evangélica y reconvertirlos al cristianismo católico, apostólico y romano mediante medios pacíficos ${ }^{68}$.

\section{La muerte del taumaturgo}

En su lecho de muerte, la Virgen María le dijo a fray Gonzalo: "Te he librado de los demonios, estás seguro del todo, cierto de tu salvación y eterna felicidad" (Villegas, 1615, p. 398v) (Croiset, 1842, p. 158). Y antes de fallecer, el portugués repitió las palabras pronunciadas por santo Domingo en la misma circunstancia: “les ayudaré más muerto que vivo" (Álvarez, 1920, pp. 221, 227) ${ }^{69}$. Como ocurrió a lo largo de toda su vida, la Virgen María lo acompañaba: “Vio a la Reyna de los Cielos, que rodeada de coros angélicos llenó la pobre casita de luz, y su alma de consuelo; y llamándole por su nombre le decía, que fuese con ella a recibir el premio a sus largos trabajos (Bordazar, 1739, pp. 45-46) ${ }^{70}$. Gonzalo de Amarante murió un 10 de enero entre 1259 y 1262. Su deceso se debió a "los inmensos trabajos que padeció y el rigor de sus penitencias"71 o quizá también debido a "una grave enfermedad" (Amado, 1829, p. 6).

68 En Galmés, el primer encuentro con un hereje en Ferrando, núm. 11, p. 226; Orvieto, núm. 12, p. 255. La búsqueda, "Actas de los testigos de Languedoc", núm. 3, p. 182, núm. 7, p. 183, núm. 13, p. 184, núm. 18, p. 185. El empeño por su conversión, núm. 26, pp. 306-307; Romans, núms. 52-53, pp. 319-320, entre otros muchos ejemplos.

69 Las palabras de santo Domingo fueron: “... que les sería más útil cuando muriera de lo que lo fuera en vida", en Galmés, 1987, Sajonia, núm. 93, p. 114; Orvieto, núm. 63, p. 275; Romans, núm. 64, p. 327; Cerrato, núm. 45, p. 360.

70 Álvarez, 1920, pp. 221, 227 y Butler, 1968, p. 112.

71 Croiset, 1842, p. 158. Villegas, 1615, p. 398v. 
Después de su muerte la ermita se convirtió en un lugar de peregrinaje regional, atendido por el clero secular. Los devotos acudían a orar a su sepulcro, atraídos por los prodigios de sus milagros. Además, a un manantial cercano, debido a sus propiedades curativas, se le relacionó con el milagro donde hizo brotar agua de una roca y Bordazar relata que: esta agua "con devoción la beben y aplican por remedio a los ojos", y "mucha gente devota la lleva a sus enfermos y afirman que es saludable" (1739, p. 30). La ermita pasó a los dominicos a mediados de siglo XVI -hacia 1540-, cuando el monarca Juan III y el cardenal de Évora la donaron a la Orden, quien construyó un templo y convento para atender a los

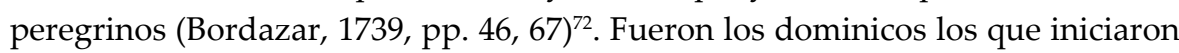
la recopilación de los milagros de san Gonzalo y los principales difusores de su devoción en los reinos y colonias de Portugal y España.

\section{Conclusiones}

A lo largo de este artículo, se demostró bibliográficamente el proceso gradual de la redacción de la vida de Amarante. Su inicio fue en Portugal con las ediciones lusitanas de la Leyenda Aurea de 1513 y 1567, donde fue incluido junto con otros venerables portugueses. En 1589, Ferdinando Del Castiglio publicó un apretado resumen -escrito en español e italiano- para su Historia General de la Orden. A partir de 1615, su biografía resumida también tuvo una importante difusión en el Imperio español a través del popular libro Flos Sanctorum, de Alonso de Villegas. En el siglo XVIII, Antonio de Vieyra (1734) publicó otro resumen y Manuel Bordazar editó una extensa biografía (1739). En el siglo XIX se sumaron -mediante los compendios del Año cristiano- los pequeños textos de Manuel Amado (1829) y del jesuita J. Croiset (1842). Finalmente, ya entrado el siglo XX, Paulino Álvarez (1920) compiló una apretada y profunda síntesis, de gran difusión en las naciones hispanoparlantes.

En cuanto a la segunda hipótesis, a través de un análisis comparativo entre las biografías de Gonzalo de Amarante y de Domingo de Guzmán, se demostró que el modelo de santidad del portugués deviene del fundador de la Orden. Esto es comprobable por la mención de actitudes y hábitos comunes en ambos, destacandose por ejemplo, el ejercicio heroico de las virtudes, el goce de los dones

72 Álvarez, 1920, pp. 225-226. El convento y templo fueron dedicados a Gonzalo de Amarante, Anónimo, 1962, p. 6. 
sobrenaturales y desde luego la permanente inclinación a predicar el Evangelio, considerando la caridad, la defensa de la fe y el motivo central de la Orden de los dominicos, la salvación de las almas. Todos estos aspectos fueron proclamados por el magisterio de Roma, primero a petición de la monarquía portuguesa y después por la Orden de Predicadores.

La relación de las hagiografías del venerable con las Escrituras es principalmente cristológica en un sentido paulino, es decir, donde el creyente está llamado a ser otro Cristo en su seguimiento del Hijo de Dios. Asimismo, destacan las tareas apostólica y profética presentes respectivamente en el Nuevo y en el Antiguo Testamento. Como se vio, la influencia de la hagiografía antigua no solo es notoria sino antigua por las referencias a san Pablo, san Hilarión y san Antonio, pioneros de la vida religiosa cristiana. Los vínculos con la hagiografía dominicana del siglo XIII son primero a través de la Virgen María -como intercesora, guía y patrona- y segundo, el apego a Domingo de Guzmán -como modelo de vida cristiana centrado en la predicación-.

Sin duda, la devoción -varias veces centenaria- a Gonzalo de Amarante tiene muy diversos aspectos por estudiar y este artículo es solo una aproximación a su relación mantenida con las fuentes bíblicas, los evangelios apócrifos y las fuentes hagiográficas primitivas y medievales. Las biografías no solo son fuentes históricas que muestran aspectos importantes de la realidad histórica del siglo XIII, sino develan mediante milagros, muchas veces fantásticos, las necesidades, aspiraciones, dolencias y esperanzas del pueblo llano y creyente, que de los siglos XVIII al XX continuó con sus devociones populares, cuyas raíces se hunden en el origen del cristianismo occidental.

\section{Referencias}

Álvarez, P. (1920). Santos, bienaventurados, venerables de la Orden de los Predicadores. T. 1, Madrid, España: Editorial Vergara, Tipografía de El Santísimo Rosario.

Amado, M. (1829). Compendio histórico de la vida de los santos canonizados y beatificados del Sagrado Orden de Predicadores. Madrid, España: Imprenta de D. Eusebio Aguado.

Anónimo. (1962). Província de Portugal da Ordem de S. Domingo. Fátima, Portugal.

Atanasio. (1995). Vida de Antonio. Madrid, España: Ciudad Nueva.

Bordazar, M. (1739). Compendio de la vida del glorioso confesor san Gonzalo de Amarante, de la Sagrada Orden de Predicadores. Va añadida la devoción de su novenario. Valencia, España: Imprenta de Antonio Bordazar.

Butler. (1968). Vidas de los santos, T. 1. México D. F., México: Collier's International. 
Calatabí, B. (1957). Spiritualitá monastica. Vita Monasticas, 57, pp. 3-57.

Castiglio, F. (1589). Historia Generale di S. Domenico e dell'Ordine suo. T. 1. Roma, Italia: Ordum Preadicatourum.

Chardon, C. (1800). Historia de los sacramentos. Madrid, España: Imprenta Real.

Chompre, M. (1783). Diccionario abreviado de la fábula para la inteligencia de los poetas, pinturas y estatuas, cuyos asuntos están tomados de la Historia Poética. Madrid, España: Manuel de Sancha.

Croiset, J. (1842). Año Cristiano o ejercicios devotos para todos los días del año... París, Francia: Librería de Leconte y Lasserre.

Fisiólogo. (2008). Pseudo Aristóteles, Fisiognomía. Anónimo. Madrid, España: Gredos.

Galmés, L; Gómez, V. (1987). Santo Domingo de Guzmán. Fuentes para su conocimiento. Madrid, España: Biblioteca de Autores Cristianos.

Mandonnet, P. (1929). Estudios religiosos. Santo Domingo, la idea, el hombre y la obra. Madrid, España: Orden de Predicadores.

Migne, J. (1884). Patrologiae cursus completus... París, Francia: Garnier Fratres Editores.

Orozco, M. (22 al 24 de abril de 2014). San Gonzalo de Amarante: bailando desde Portugal a Nueva España, I Congreso Internacional de Historia de la Orden de Predicadores en América (inédita).

Piñero, A., y del Cerro, G. (2005). Hechos apócrifos de las apóstoles, hechos de Pablo y Tomás. T. 2. Madrid, España: Biblioteca de Autores Cristianos.

Rivas, F. (1994). La Vita Hilarionis y la vida de San Jerónimo. CuadMon 109.

Santos, A. (1963). Los evangelios apócrifos. Madrid, España: Biblioteca de Autores Cristianos.

Tourón, A. (1826). Vida de santo Domingo de Guzmán, fundador de la Orden de Predicadores con un compendio de la historia de sus primeros discípulos. Madrid, España: Imprenta de E. Aguado.

Villegas, A. (1615). Flos Sanctorum, y historia general de la vida de Iesu Christo, Dios y Señor nuestro, y de todos los Santos, de que se reza y haze fiesta la Iglesia Catolica, conforme al Breviario Romano, reformado por decreto del santo Concilio Tridentino: junto con las vidas de los santos propios de España, y de otros extravagantes... Barcelona, España: Sebastián de Cormellas.

Vogüé, A. (1991). Jerome et sa Vie de Saint Paul. Histoire littéraire du mouvement monastique dans l'antiquité. V. I. París, Francia: Cerf. 